\title{
Use of Prescription Drugs and Investigations by Doctors in Primary Care Settings in Oman and the UK
}

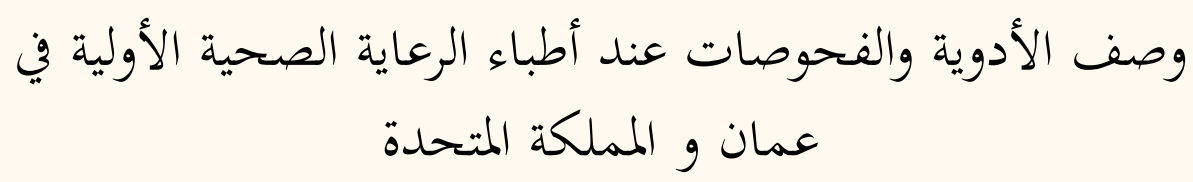

روين ديفيدسون

ABSTRACT: Objectives: This audit aimed to investigate the use of prescription drugs and investigations by trainee doctors in primary care settings in Oman and the UK. Methods: This audit took place between February and April 2015. The medical records of consecutive patients seen by five family medicine trainee doctors at a primary care setting in Oman were retrospectively reviewed. These data were compared to those gathered from two trainees at a general practice clinic in the UK as well as an experienced general practitioner (GP) who had practiced in both countries. Results: The average number of items prescribed per patient was 1.19, 0.43 and 0.24 and the rate of investigations was $20 \%, 21 \%$ and $11 \%$ for Omani trainees, UK trainees and the GP, respectively. Conclusion: This audit suggests that family medicine trainees in Oman prescribe almost three times as many drugs as trainees in the UK. The findings also point towards an over-investigation of the relatively young Omani patient population.

Keywords: Prescriptions; Health Resources; Primary Health Care; Oman; United Kingdom.

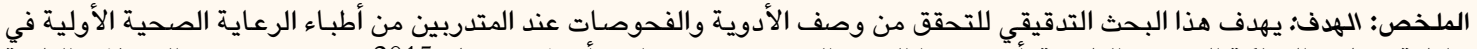

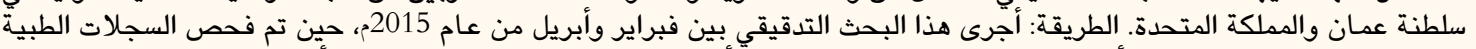

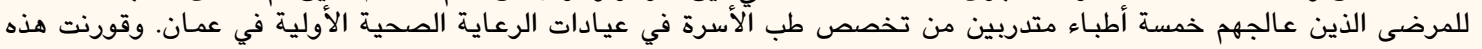

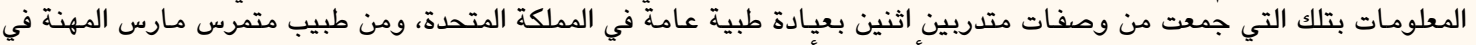

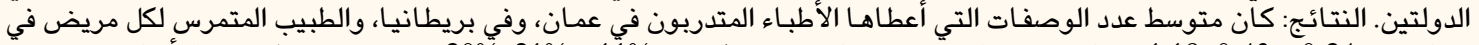

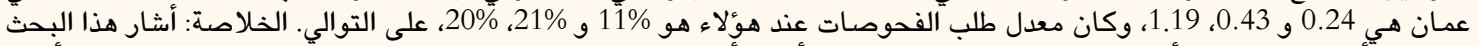

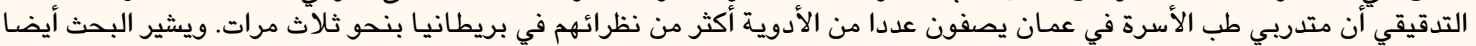

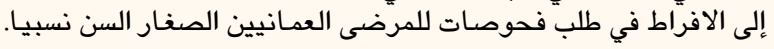
الكلمات المفتاحية: الوصفات الطبية؛ الموارد الطبية؛ الرعاية الصحية الأولية؛ عمان؛ المملكة المتحدة.

$\mathrm{T}$ He RISING COST OF HEALThCARE AROUND the world is a source of increasing concern for many governments. ${ }^{1,2}$ Although there are many factors driving this trend at both the national and international levels, every doctor has a responsibility to justify ordering investigations and prescription medications. Patient demand and a consumerist approach to healthcare puts pressure on doctors to investigate and prescribe more; however, this may not always be in a patient's best interests and can lead to overdiagnosis and the development of iatrogenic disease. .,4 $^{3,4}$

The National Health Service (NHS) in the UK has struggled with these problems for years and doctors working within the NHS-especially in primary care-have become increasingly aware of the predictive value of investigations and the cost-effectiveness of medical treatments. ${ }^{5}$ In Oman, doctors often want to offer, and patients increasingly expect to receive, the latest treatments and investigations. Although these are often more expensive, they are not always more effective; to this end, the World Health Organization (WHO) runs a programme promoting the rational use of medicines in countries where polypharmacy is a major problem. ${ }^{6}$

It is important that doctors in training have an appreciation of these financial issues in order to carry forward best medical practices. The UK and Omani governments both provide socialised comprehensive national health services to all citizens, free at the point of delivery. ${ }^{7,8}$ Additionally, in both countries, primary care physicians are the gateway to secondary care services and have easy access to blood tests, medical imaging and clinical physiology tests. Trainees in 


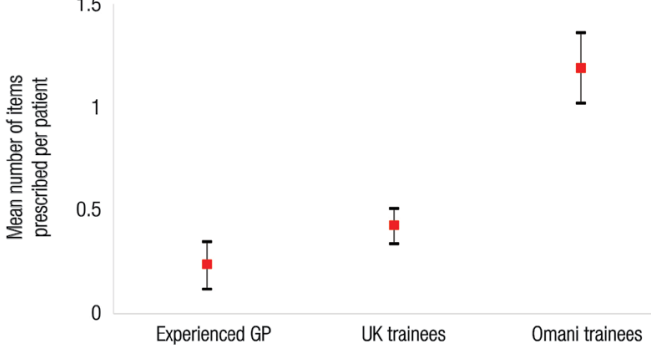

Figure 1: Mean number of items prescribed per patient by five trainee doctors in Oman, two trainee doctors in the UK and an experienced general practitioner. The error bars indicate $95 \%$ confidence intervals.

$G P=$ general practitioner

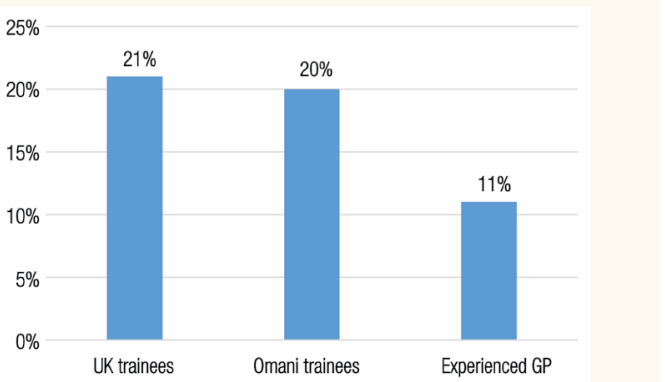

Figure 2: Rate of investigations by five trainee doctors in Oman, two trainee doctors in the UK and an experienced general practitioner.

$G P=$ general practitioner

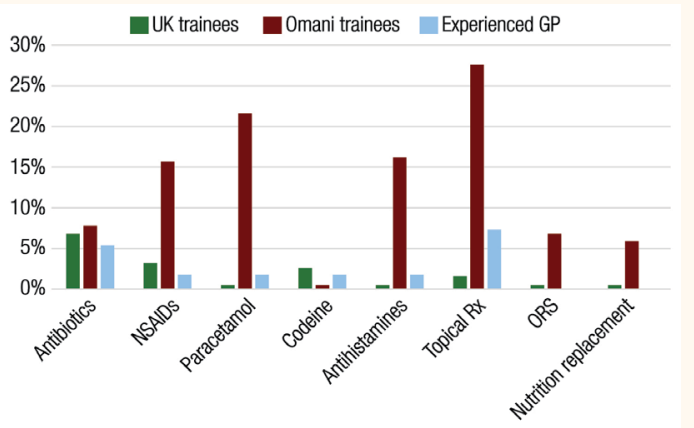

Figure 3: Drugs prescribed by category by five trainee doctors in Oman, two trainee doctors in the UK and an experienced general practitioner.

$G P=$ general practitioner $;$ NSAIDs $=$ non-steroidal anti-inflammatory drugs; $R x=$ prescriptions; $O R S$ = oral rehydration solutions.

both countries face similar challenges as they move from the disease-centred and systematic approach of hospital practice to a more patient-centred and focused approach in family medicine. This audit therefore aimed to compare the use of resources (i.e. prescription drugs and investigations) by trainee doctors in primary care settings in Oman and the UK.

\section{Methods}

This audit was carried out between February and April 2015. A retrospective review was conducted of the medical records of consecutively attending patients in February and March 2015 seen by five final year trainees at the Family \& Community Medicine clinic of Sultan Qaboos University Hospital in Muscat, Oman. As there is no international benchmark for rates of prescription and investigations, these data were compared with those of two trainees from St Augustine's Medical Practice, Bristol, UK, and an experienced general practitioner (GP) who had practised medicine in both Oman and the UK. The data from the UK trainees were collected in the same way and during the same time period as that of the Omani trainees. For the experienced GP, only data on patients seen in the UK in April 2015 were used in the analysis.

The audit examined the number of items prescribed per patient and the percentage of patients who underwent investigations for all three groups. The number and category of drugs prescribed was also analysed. Only patients presenting with medical conditions requiring same day consultations were included. Data for the three groups were compared using means and 95\% confidence intervals (CIs).

\section{Results}

Overall, the records of 347 patients were reviewed, including 102 patients (29\%) seen by trainees in Oman, 190 patients (55\%) seen by trainees in the UK and 55 patients (16\%) seen by the experienced GP. The average age of patients seen by the Omani trainees was 26.1 years compared to 46.9 years for patients seen by the UK trainees and 47.2 years for patients seen in the UK by the experienced GP.

The Omani trainees prescribed a mean of 1.19 items per patient (95\% CI: $1.02-1.36)$ compared to 0.43 items per patient (95\% CI: 0.34-0.51) prescribed by trainees in the UK and 0.24 items per patient (95\% CI: 0.12-0.35) prescribed by the experienced GP [Figure 1]. Investigations were carried out on $20 \%$ of patients (95\% CI: 12-27\%) seen by trainees in Oman compared with $21 \%$ of patients (95\% CI: $15-27 \%$ ) seen by trainees in the UK and $11 \%$ of patients $(95 \% \mathrm{CI}$ : 2-20\%) seen by the experienced GP [Figure 2]. Figure 3 shows the percentage of drugs prescribed according to drug category for all three groups. 
Table 1: Comparison of prescription and investigation practices of trainee doctors in Oman and the UK and an experienced general practitioner with an international benchmark

\begin{tabular}{|c|c|c|c|c|c|}
\hline & $\begin{array}{l}\text { Number of } \\
\text { trainees/GPs }\end{array}$ & $\begin{array}{c}\text { Number of } \\
\text { patients seen }\end{array}$ & $\begin{array}{l}\text { Average age of } \\
\text { patient in years }\end{array}$ & $\begin{array}{c}\text { Mean number } \\
\text { of items } \\
\text { prescribed per } \\
\text { patient }\end{array}$ & $\begin{array}{c}\text { Rate of } \\
\text { investigations }\end{array}$ \\
\hline UK trainees & 2 & 190 & 46.9 & 0.43 & $21 \%$ \\
\hline Omani trainees & 5 & 102 & 26.1 & 1.19 & $20 \%$ \\
\hline Experienced GP* & 1 & 55 & 47.2 & 0.24 & $11 \%$ \\
\hline Kinnersley et al. ${ }^{11} 2000$ & 10 NHS practices & 711 & 30.0 & 0.61 & $10 \%$ \\
\hline
\end{tabular}

\section{Discussion}

As might be expected, the current audit showed that the experienced GP had lower rates of prescriptions and investigations than either group of trainees. There was no significant difference in the rates of investigation between the two groups of trainees in the current audit, although the average age of patients in Oman was much lower, which might point to overinvestigation. Omani trainees prescribed almost three times as many drugs as UK trainees in the present audit. However, this finding needs to be interpreted with caution; although there are many similarities between primary care settings in Oman and the UK, it is important to recognise that prescription charges apply for certain patients or specific drugs in the UK.? Although these fees apply to only approximately 10\% of prescriptions, it has led to an expectation that many symptomatic treatments can be purchased over-thecounter by the patient from pharmacies, decreasing the pressure on the physician to prescribe such medications. ${ }^{9}$ Indeed, in the current audit, the majority of items prescribed in Oman were symptomatic treatments and most likely prescribed for self-limiting illnesses, while the rates of antibiotic prescribing were similar among all three groups.

Prescribing rates are collected and reported by the WHO; however, this includes long-term drugs used in the treatment of chronic diseases and thus cannot be used as an international standard. ${ }^{6}$ In 1989, Hogerzeil et al. reported that the number of drugs prescribed per patient ranged from 1.4-3.8 in developing countries and 1.3-2.2 in developed countries..$^{10}$ In 2000, Kinnersley et al. measured the prescription and investigation practices of GPs from 10 NHS practices; the findings indicated that the GPs prescribed an average of 0.61 items per patient and carried out investigations for approximately $10 \%$ of patients. ${ }^{11}$ Although not the primary objective of this research, this is the only study in the literature that can be regarded as a benchmark to compare with the findings of the current audit [Table 1]. ${ }^{11}$ Within the Arab region, research from Iran in 2010 indicated a rate of 3.34 items prescribed per patient, while a study from Yemen in the same year reported a rate of 2.65 items prescribed per patient. ${ }^{12,13}$ However, these data should be only regarded as indicative of possible trends as it is not entirely clear whether these studies were conducted in similar primary care populations. ${ }^{12,13}$

This audit suggests the overuse of some prescription drugs by Omani trainees; moreover, the average age of the patients seen in Oman was much lower than that of the UK trainees or the experienced GP, indicating the existence of a younger patient population. Further formal comparative studies with larger sample sizes are required to explore the underlying reasons for the apparent over-prescription of certain drugs by trainees in Oman. Nevertheless, it is important to note that, although the health services available in Oman and the UK are similar, there are profound differences in lifestyle and culture. Patients' understanding of health issues and their expectations of treatment are also very different; as such, there may be considerable pressure on young doctors in Oman to prescribe and investigate, sometimes inappropriately.

There were several limitations to this audit. First, the number of trainees involved was small, as was the number of patients; this is especially true for the number of patients seen by the experienced GP, as senior doctors tend to have fewer same day consultations. Second, the data were gathered by individual doctors who manually reviewed the patients they had seen each day; therefore, the data may have been subject to errors and omissions. Automatic and electronic data collection systems would be likely to yield more reliable results. 


\section{Conclusion}

This simple audit suggests that family medicine trainees in Oman prescribe almost three times more drugs than GP trainees in the UK. Additionally, the findings seem to point towards the over-investigation of a much younger patient population in Oman.

\section{CONFLICT OF INTEREST}

The author declares no conflicts of interest.

\section{FUNDING}

No funding was received for this audit.

\section{ACKNOWLEDGEMENTS}

The author is grateful to his colleagues at St Augustine's Medical Practice for collecting the data on the UK trainees. The author would also like to acknowledge that the experienced GP in the current study is himself.

\section{References}

1. Organisation for Economic Co-operation and Development. Focus on health spending: OECD health statistics 2015. From: www.oecd.org/health/health-systems/Focus-Health-Spend ing-2015.pdf Accessed: Aug 2016.

2. Berwick DM, Hackbarth AD. Eliminating waste in US health care. JAMA 2012; 307:1513-16. doi: 10.1001/jama.2012.362.

3. Fang H, Miller N, Rizzo J, Zeckhauser R. Demanding customers: Consumerist patients and quality of care. From: www.nber.org/ papers/w14350.pdf Accessed: Aug 2016.
4. Grady D, Redberg RF. Less is more: How less health care can result in better health. Arch Intern Med 2010; 170:749-50. doi: 10.1001/archinternmed.2010.90

5. Nuffield Trust. NHS in numbers. From: www.nuffieldtrust.org. uk/nhs-numbers-0 Accessed: Aug 2016.

6. World Health Organization. The pursuit of responsible use of medicines: Sharing and learning from country experiences. From: apps.who.int/iris/bitstream/10665/75828/1/WHO_EM P_MAR_2012.3_eng.pdf Accessed: Aug 2016.

7. Boyle S. Health systems in transition: United Kingdom (England) health system review 2011. From: www.euro.who. int/_data/assets/pdf_file/0004/135148/e94836.pdf Accessed: Aug 2016.

8. World Health Organization Regional Health Systems Observatory. Health system profile: Oman. From: apps.who. int/medicinedocs/documents/s17304e/s17304e.pdf Accessed: Aug 2016.

9. Health and Social Care Information Centre. Prescriptions dispensed in the community: England 2004-14. From: www. hscic.gov.uk/catalogue/PUB17644/pres-disp-com-eng-200414-rep.pdf Accessed: Aug 2016.

10. Hogerzeil HV, Walker GJ, Sallami AO, Fernando G. Impact of an essential drugs programme on availability and rational use of drugs. Lancet 1989; 1:141-2. doi: 10.1016/S0140-6736 (89)91152-5.

11. Kinnersley P, Anderson E, Parry K, Clement J, Archard L, Turton P, et al. Randomised controlled trial of nurse practitioner versus general practitioner care for patients requesting "same day" consultations in primary care. BMJ 2000; 320:1043-8. doi: 10.1136/bmj.320.7241.1043.

12. Safaeian L, Mahdanian A, Hashemi-Fesharaki M, Salami S, Kebriaee-Zadeh J, Sadeghian GH. General physicians and prescribing pattern in Isfahan, Iran. Oman Med J 2011; 26:205-6. doi: 10.5001/omj.2011.50.

13. Bashrahil KA. Indicators of rational drug use and health services in Hadramout, Yemen. East Mediterr Health J 2010; 16:151-5. 